\title{
Heat Flux Distribution and Flame Shapes on the Inert Facade
}

\author{
YEE-PING LEE ${ }^{1,2}$, M. A. DELICHATSIOS ${ }^{2}$ and G.W.H. SILCOCK ${ }^{2}$ \\ 1: Department of Civil \& Environmental Engineering, Nanya Institute of Technology, Taiwan \\ 2: The Institute for Fire Safety Engineering Research and Technology (FireSERT), University of \\ Ulster, U.K.
}

\begin{abstract}
Fire spread in high rise buildings from floor to floor occurs if flames emerge and extend on the façade of the building to cause ignition in the floor above the floor where flashover has developed. Even though considerable effort has been exerted to address this issue, proposed relations for heat fluxes on façade are incomplete and contradictory because the relevant physics have been poorly clarified. By systematically performing a series small scale experiments having various enclosure geometries, door-like openings and fire locations, the physics and new relations are underpinned for the emerging flames on inert facades in ventilation controlled (under-ventilated) fires at the floor of fire origin. To limit the variables and uncertainties, propane and methane gas burners create a controlled (theoretical) heat release rate at the source. Gas temperatures inside the enclosure and at the opening, heat fluxes on the façade wall, flame contours (by a Charge Coupled Device camera-CCD camera) and heat release rates (by oxygen calorimetry) inside and outside the enclosure have been measured. The gas temperatures inside the enclosure were uniform for aspect ratio (length to width) of the enclosure from one to one to three to one. Previous relations for the air inflow and heat release rate inside the enclosure were verified. The flames are highly radiative because soot can be formed at high temperatures inside the enclosure before the combustion gases and the unburned fuel exit the enclosure. The heat fluxes on an inert façade, both at the centreline and off-center above the opening, have been well correlated by identifying two length scales. One related to the effective area of the outflow $\left(\ell_{1}\right)$, and the other represented the length after which the flames turn from horizontal to vertical $\left(\ell_{3}\right)$. Finally, Correlation of the maximum flame width which is valid for the case having aspect ratio of the opening (width to height) between 0.375 and 2 was proposed in this paper. The results can be used for engineering calculations for real fires and for validation of new large eddy scale simulation models.
\end{abstract}

KEYWORDS: compartment fires, heat release rate, heat flux, flame width

NOMENCLATURE LISTING

\begin{tabular}{|c|c|c|c|}
\hline A & Area of the opening $\left(\mathrm{m}^{2}\right)$ & $\mathrm{T}_{\infty}$ & Ambient air temperature $\left({ }^{\circ} \mathrm{C}\right.$ or $\left.\mathrm{K}\right)$ \\
\hline$c_{p}$ & Specific heat at constant pressure & $\mathrm{W}$ & Width of the opening (m) \\
\hline $\mathrm{g}$ & Acceleration due to gravity $\left(\mathrm{m} / \mathrm{s}^{2}\right)$ & $\mathrm{Z}_{\mathrm{f}}$ & Mean flame height (m) \\
\hline $\mathrm{H}$ & Height of the opening (m) & Greek & \\
\hline$\dot{\mathrm{m}}_{\mathrm{a}}$ & Mass rate of air inflow $(\mathrm{kg} / \mathrm{s})$ & $\ell_{1}$ & $\begin{array}{l}\text { Length scale related to the effective area of the outflow } \\
\text { for under-ventilated fires }(\mathrm{m})\end{array}$ \\
\hline$\dot{\mathrm{q}}_{\mathrm{t}}^{\prime \prime}$ & Total heat flux $\left(\mathrm{kW} / \mathrm{m}^{2}\right)$ & $\ell_{2}$ & $\begin{array}{l}\text { Length scale represented the length after which the } \\
\text { flow (hot gas) turns from horizontal to vertical due to } \\
\text { buoyancy for under-ventilated fires (m) }\end{array}$ \\
\hline$\dot{\mathrm{Q}}_{\mathrm{encl}}$ & Heat released inside the enclosure $(\mathrm{kW})$ & $\ell_{3}$ & $\begin{array}{l}\text { Length scale represented the length after which flames } \\
\text { turn from horizontal to vertical due to buoyancy for } \\
\text { under-ventilated fires }(\mathrm{m})\end{array}$ \\
\hline$\dot{\mathrm{Q}}_{\text {ext }}$ & $\begin{array}{l}\text { Heat released outside the enclosure due } \\
\text { to combustion of unburned fuel }(\mathrm{kW})\end{array}$ & $\rho$ & Density of the steel plate $\left(\mathrm{kg} / \mathrm{m}^{3}\right)$ \\
\hline$\dot{\mathrm{Q}}_{\mathrm{rad}}^{\prime \prime}$ & Radiative heat release rate $(\mathrm{kW})$ & $\delta$ & Thickness (m) \\
\hline$\dot{\mathrm{Q}}_{\mathrm{T}}^{\prime \prime}$ & $\begin{array}{l}\text { Heat release rate for complete } \\
\text { combustion }(\mathrm{kW})\end{array}$ & & \\
\hline
\end{tabular}




\section{INTRODUCTION}

Several experiments have been conducted to investigate the heat exposure to a wall from different configurations. Such as flames at a line fire against a wall [1]; a vertical burner flush with the bottom of a wall [2,3], and flames emerging from an opening of an enclosure [4-6]. The first configuration is similar to the flow on façade of excess unburned fuel exhausting from the opening of an enclosure. It does not however represent exactly façade flames ejected from an opening since the flames are ejected horizontally before they turn upwards. In addition, the flammable gases ejected from the opening in the façade configuration have been preheated in the enclosure whereas the flammable gas from a line or vertical burner flush with the bottom of the wall is supplied at ambient temperature. Therefore, the soot production in the latter case does not reflect the level of soot developed for the fire gases ejecting from the opening of a burning room. Detailed examination of previous works [4-7] dealing with heat flux on façade owing to window flames, it is seen that only experimental results were presented and discussed but no correlations were presented. In addition, most of the previous experiments concerning heat fluxes on the façade due to fire plume were conducted using enclosures of fixed geometry and burner location. Thus, in order to investigate the influence of enclosure and opening geometry as well as the soot tendency of the fuel on the heat fluxes exposed on the façade, a reduced scale model of variable room geometry, opening geometry, fire sizes and fire location inside the enclosure using different soot tendency fuel as heat source was designed.

In previous research, heat fluxes were only measured at the centreline above the opening using commercial heat flux gauge (i.e. Gardon Gauge). To map the heat flux distribution on a façade, new and inexpensive heat flux gauges were designed and installed at several locations in the façade. A Steel plate apparatus, which is reliable, robust and much less expensive compared with commercial gauge, has been previously employed to measure total heat flux on enclosure walls or ceiling [8-12]. However, some uncertainties related to the conduction losses from the steel plate to surrounding insulation still exist [8-12]. To overcome these uncertainties, a modified steel plate was designed and calibrated by comparing steel plate heat fluxes with that measured by the Gardon gauge.

Three different enclosures with door like openings were chosen as described in the next section including an introduction of a modified steel plate heat flux gauge and description the experimental procedure. The fire source was a gas burner using methane and/or propane. Subsequently, the results for actual heat release rate, gas temperatures, heat fluxes (both at the centreline and off-center above the opening) and flame width are presented followed by an analysis of the physics and corresponding correlations. Moreover, flame shapes on external façade and their relationship with the correlation results of flame height were presented in this research. The last section presents the main conclusions of this research.

\section{EXPERIMENTAL SET-UP AND PROCEDURE}

Three different enclosure geometries numbered 1,2 and 3, made of fibreboard walls were used, having a front face $0.5 \mathrm{~m} \times 0.5 \mathrm{~m}$ and depth $0.5 \mathrm{~m}, 1 \mathrm{~m}$ and $1.5 \mathrm{~m}$ respectively. They were assembled from cubic modules of size $0.5 \mathrm{~m} \times 0.5 \mathrm{~m} \times 0.5 \mathrm{~m}$ each. The openings at the front face were all door like and centred having the following widths and heights respectively: $0.075 \mathrm{~m} \times 0.2 \mathrm{~m}, 0.1 \mathrm{~m} \times 0.2 \mathrm{~m}, 0.2 \mathrm{~m} \times 0.2 \mathrm{~m}$ and $0.3 \mathrm{~m}$ $\mathrm{x} 0.1 \mathrm{~m}$. Propane and methane rectangular sandbox burners were the fuel source to precisely regulate the fuel supply rate by a mass flow controller. The locations of the burners were at the centre of each module as shown by the notation A, B, and C in Figure 1. For each enclosure geometry, experiments were run with the burner at each of the locations A, B and C as shown in Fig. 1 and detailed in Table 1. The external façade was constructed by fibreboard plates as shown in Fig. 2, which also shows the instrumentation of heat flux gauges on the façade.

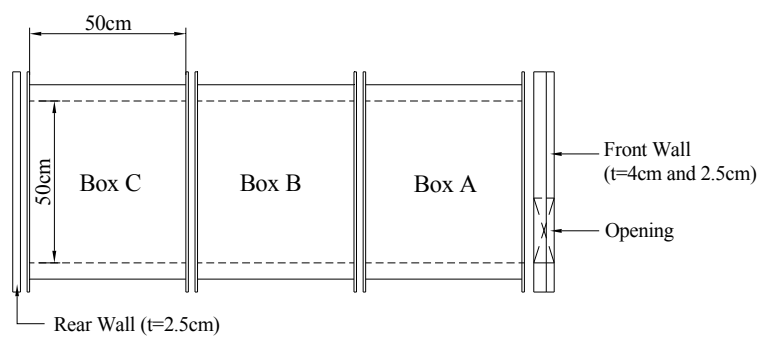

Fig. 1. Geometry of three enclosures 1 (one box,A), 2(two boxes, $\mathrm{A}+\mathrm{B}$ ), 3(three boxes, $\mathrm{A}+\mathrm{B}+\mathrm{C}$ ) 
Table 1. Experimental conditions (the dots represents the location of the thermocouple tree)



Fig. 2. The front view of the experimental apparatus (unit: $\mathrm{cm}$ )

\section{The measurements included:}

1. Gas Temperatures

Gas temperatures inside the enclosure were measured by thermocouple trees having six $1.5 \mathrm{~mm}$ type $\mathrm{K}$ thermocouples with position $10 \mathrm{~cm}$ apart at two corners as indicated in Table 1.

2. Heat Release Rate

Actual heat release rate from the assembly of the enclosure and façade were obtained by placing the assembly under a calorimeter hood and analysing the combustion gases [13].

3. Flame height:

A CCD camera and an image-processing technique were employed to map flame presence probability and to determine the extent of the external combustion $[14,15]$. The image processing technique (CCD camera) to determine locations where the flame presence probability is equal to $50 \%$ was validated both by determining the center of the maximum standard deviation of fluctuations and by measuring the local flame gas temperature to be $500^{\circ} \mathrm{C}[16,17]$. Accepting the so established methodology to measure the flame heights and widths, the uncertainty is less than $2 \%$.

4. Total heat fluxes on the façade:

The apparatus with thermocouples spot-welded to the back of the steel plate has been previously employed in Ref. 8-12 for heat flux measurement. However, some uncertainties in measuring heat 
flux by this method have not been clarified as yet. Thus, to overcome this defect, a modified steel plate methodology (see the experimental procedure below) was developed in this research to measure total heat fluxes on the façade as shown in Fig. 2. All the gauges identical in design were used because they are easier to install and less expensive than the Gardon gauges. The methodology to deduce the heat fluxes using the steel plate gauge was validated by those measured by the Gardon gauge both in selected places in the present tests (see the steel plate labelled as U and L in Fig.2) and also in measurements in the cone calorimeter $[12,16,17]$ ( uncertainty less than $2 \%$ ). The details of the steel plate gauge (dimensions $25 \mathrm{~mm}$ by $25 \mathrm{~mm}$ by $5 \mathrm{~mm}$ ) embedded flush to the surface of the façade insulation and a type $\mathrm{K}$ thermocouple wire spot-welded to the its rear surface is illustrated in Fig. 3.

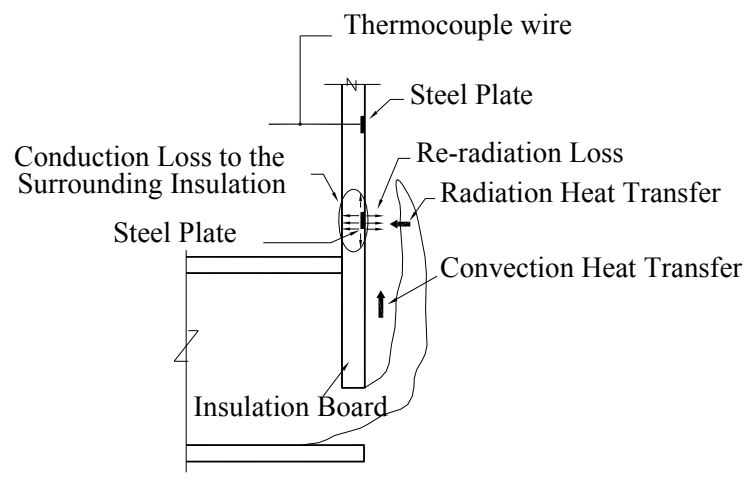

Fig. 3. Details of the steel plate gauge.

\section{The experimental procedure was designed to establish steady state conditions inside the enclosure} was achieved as follows:

a) By increasing the flow rate of the fuel (or theoretical heat release rate) at a fixed rate after its ignition until the desired flow was reached, and the gas temperatures in the enclosure reached a plateau. This procedure took about 15 minutes.

b) To deflect the flames and thereby prevent the flames from impinging on the façade and imposing a heat flux on the steel plate gauges, a horizontal ceramic fibreboard plate (see Fig. 2) was placed over the opening when flames start to appear outside of the opening.

c) The horizontal fibreboard was removed after quasi-steady conditions were established in the enclosure and the flames were now attached to the façade exposing the heat flux gauges suddenly to the heat flux from the flames. The total heat fluxes on the façade can then only be calculated by averaging the results calculated by the energy storage equation shown in Eq.1 over 50 second time period immediately after exposure. The advantage for this experimental procedure is that the reradiation and conduction losses from the steel plate (see Fig. 3) are negligible because steel plate temperature is still low at the time when the horizontal plate just removed.

$\dot{\mathrm{q}}_{\mathrm{t}}{ }^{\prime \prime}=\rho \mathrm{C}_{\mathrm{p}} \delta \frac{\mathrm{dT}}{\mathrm{dt}}$

Where $\rho, \mathrm{C}_{\mathrm{p}}$ and $\delta$ are the density, specific heat and thickness of the steel plate, respectively. The derivative, $\frac{\mathrm{dT}}{\mathrm{dt}}$, is determined from the measured steel plate temperature.

All the experimental tests and conditions are summarised in Table 1.

\section{EXPERIMENTAL RESULTS}

\section{Heat Released Rate inside the Enclosure}

To simulate the real fire scenario where the gas temperature increase with time and can reach a quasisteady state for fully developed fire conditions, we increased the flow rate of the gas in the burner by small steps until the designed steady (maximum) value was reached. Figure 4a shows the history of actual heat 
release rate (measured by calorimeter) and theoretical heat release rate (calculated by heat of combustion of fuel times the gas flow rate). It is seen that the theoretical and actual values are the same before the first plateau is reached in the actual heat release rate. During this plateau period, flames existed only inside the enclosure with excess pyrolysate escaping outside the enclosure (for example, the theoretical HRR equals to $37 \mathrm{~kW}$ at the end of the intermediate plateau in Fig. 4a) until it ignited after a certain time. After this ignition the measured heat release rate jumped up to the value corresponding to the designed steady state heat release rate. Inspection and comparison shows that the first plateau value of the actual heat release rate is equal to $1500 \mathrm{AH}^{1 / 2}(\mathrm{~kW})$. The same behaviour was observed for all openings and unexpectedly all enclosure geometries employed in this research (see Figure $4 \mathrm{~b}$ and $4 \mathrm{c}$ ). This implies that the heat released inside the enclosure in the case of under-ventilated fires can be calculated using the equation below, which verifies the prediction presented in previous work $[6,18]$.

$\dot{\mathrm{Q}}_{\mathrm{encl}}=1500 \mathrm{AH}^{1 / 2} \mathrm{~kW}$

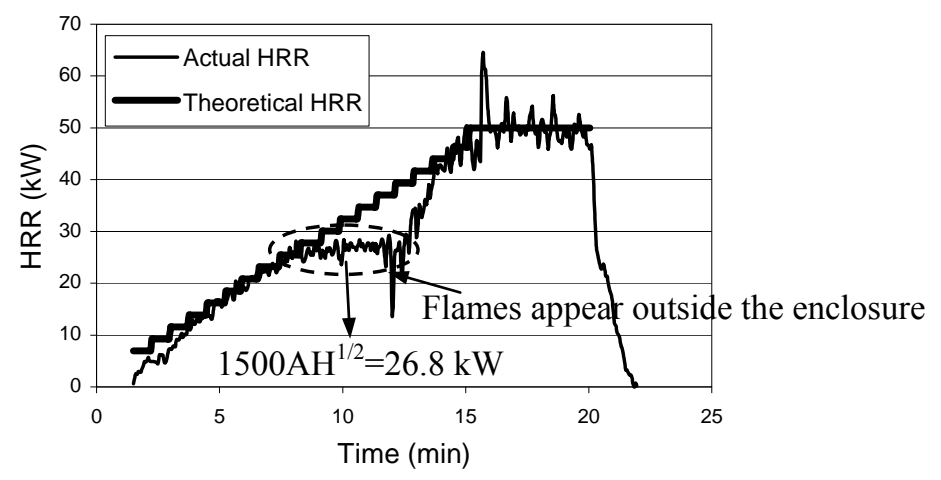

Fig. 4a. Theoretical and measured heat release rate history for the experiment having $20 \mathrm{~cm}$ by $20 \mathrm{~cm}$ opening. The first plateau indicts the HRR inside the enclosure and is equal to $26.8 \mathrm{~kW}$.
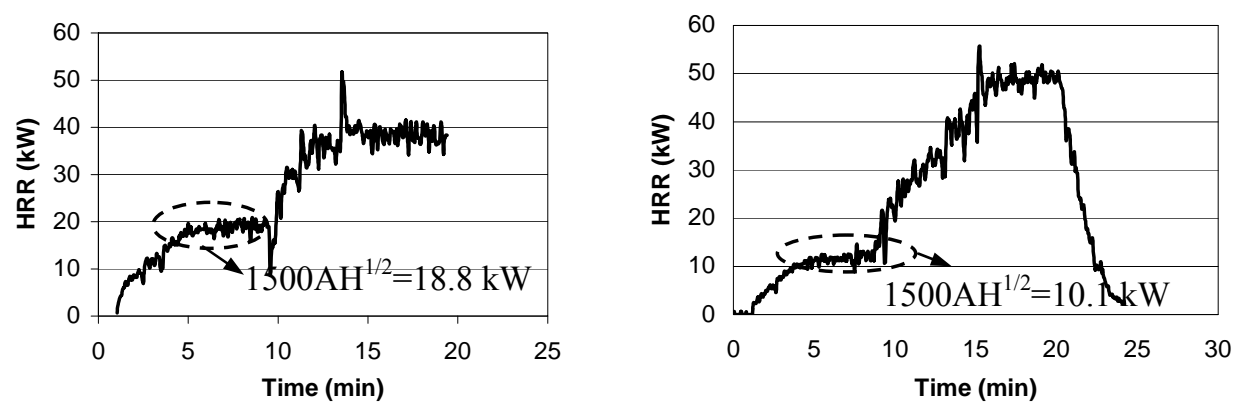

Fig. $4 \mathrm{~b}$. HRR profile for the experiment having $2 \mathrm{~B}$ enclosure geometry (see Table 1 ) and $0.1 \mathrm{~m}$ by $0.25 \mathrm{~m}$ opening with theoretical HRR $40 \mathrm{~kW}$.

Fig. 4c. HRR profile for the experiment having $3 \mathrm{C}$ enclosure geometry (see Table 1 ) and $0.075 \mathrm{~m}$ by $0.2 \mathrm{~m}$ opening with theoretical HRR $50 \mathrm{~kW}$.

Figure 5 shows the temperature distribution inside the enclosure for all of the experiments having $20 \mathrm{~cm}$ by $20 \mathrm{~cm}$ opening. The temperatures were averaged over 2 minutes period after quasi-steady state conditions are reached. It is observed that the qusi-steady state gas temperature inside the enclosure is quite uniform from top to the floor of the enclosure for each enclosure geometry. Moreover, the gas temperatures inside the enclosure do not essentially depend on the supplied theoretical heat release rate for the experiments having same opening and same enclosure geometry. Additional, observations were made from experimental work conducted in this research where the heat released inside the enclosure only depends on opening geometry and regardless of enclosure geometry, burner location and theoretical heat release rate. It is quite close to $1500 \mathrm{~A} \sqrt{\mathrm{H}}(\mathrm{kW})$ as shown in Fig. 4. This behaviour implies that the mass inflow of air at the opening is controlled by the opening geometry which equals 
to $0.5 \mathrm{AH}^{1 / 2}(\mathrm{~kg} / \mathrm{s})[21]$ and all oxygen in the air is consumed inside the enclosure $\left(\Delta \mathrm{H}_{\text {air }}=3000 \mathrm{~kJ} / \mathrm{kg}\right)$ for the under-ventilated fire condition (Eq.2).



Fig. 5. Vertical temperature distribution measured by the front thermocouple tree for all fires and all enclosures having opening size $0.2 \mathrm{~m}$ by $0.2 \mathrm{~m}(1,2,3$ represent the one box, two boxes and three boxes enclosures).

\section{Heat Flux Distribution}

Figure 6 shows heat flux distributions along the centerline above the opening against the value of $\mathrm{Z} / \mathrm{Z}_{\mathrm{f}}$ for experiments having various room geometries and burner locations, where $\mathrm{Z}$ and $\mathrm{Z}_{\mathrm{f}}$ are the location of the heat flux gauge in the external façade and the measured flame height, respectively. Both $Z$ and $Z_{\mathrm{f}}$ are measured from the position of the neutral plane which is $0.4 \mathrm{H}$ above the bottom of the opening[16]. The flame height data, obtained by CCD camera and an image-processing technique, and their correlation has been presented elsewhere [16, 17]. The heat flux distributions are similar in the experiments having same opening factor and fuel supply rate (i.e. theoretical HRR) regardless of the burner location and enclosure geometry (Fig. 6a) except for the one having a cubic geometry and $0.2 \mathrm{~m}$ by $0.2 \mathrm{~m}$ opening where a higher heat flux distributions were measured at locations near the top of the opening (Fig. 6b). A possible explanation for this is that experiments with $0.2 \mathrm{~m}$ by $0.2 \mathrm{~m}$ opening and one box enclosure geometry always reached the higher enclosure temperatures (above $1300 \mathrm{~K}$ ) compared with those having small opening geometries or rectangular enclosure geometries [16]. The high enclosure temperature preheats the fuel inside the enclosure. The gaseous fuel then was decomposed and facilitated the formation of soot particles exhausted with flames outside of the opening. This decomposition of gaseous fuel due to the effect of preheat was reported by Delichatsios et al. previous research [19]. This phenomenon is confirmed by the observation during the experiments that severe smoke was generated in the case having one box enclosure geometry and $0.2 \mathrm{~m}$ by $0.2 \mathrm{~m}$ opening where sooty flames causes higher radiation heat transfer from flame to the façade.

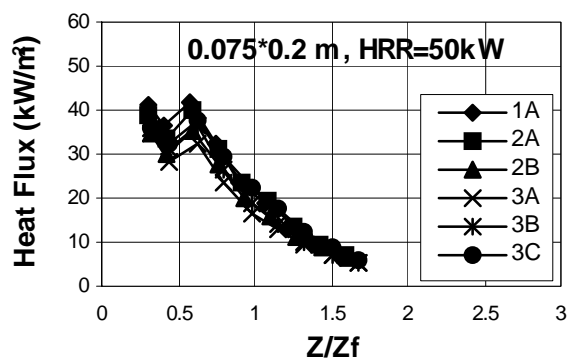

Fig. 6a

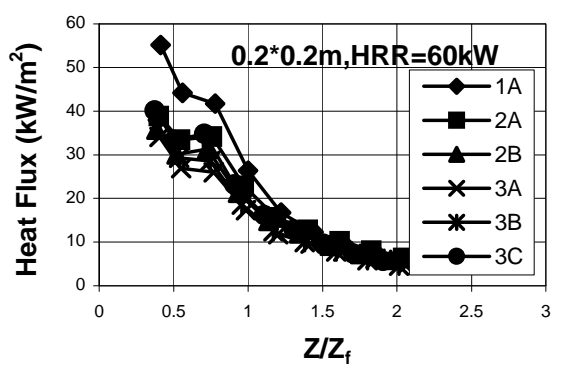

Fig. 6b

Fig. 6a. Heat flux distribution along the centreline above the opening for the experiments having $0.075 \mathrm{~m}$ by $0.2 \mathrm{~m}$ opening and using propane as fire source with theoretical HRR $50 \mathrm{~kW}$.

Fig. 6b. Heat flux distribution along the centreline above the opening for the experiments having $0.2 \mathrm{~m}$ by $0.2 \mathrm{~m}$ opening and using propane as fuel source with theoretical HRR $60 \mathrm{~kW}$.

(Note: "1, 2 and 3" represents enclosure geometry; "A, B and C" represents burner location) 
Figure 7 shows the comparison of heat flux distributions along the centerline above the opening between methane and propane fuel experiments. It can be observed that heat fluxes are close at the location of the tip of mean flame height $\left(Z / Z_{f}=1\right)$ for both fuel experiments (see Figure $\left.7 a, 7 b\right)$ except in the cases of the experiment having $0.2 \mathrm{~m}$ by $0.2 \mathrm{~m}$ opening and high fuel supply rate (i.e. $50 \mathrm{~kW}$ and $60 \mathrm{~kW}$ HRR, see Figure 7c). This difference might be due to the heavy soot developed in these propane fuel experiments, which causes higher radiation heat transfer to the façade compared with that in methane fuel experiment. Heat fluxes at the location of mean flame height $\left(Z / Z_{f}=1\right)$ increases with HRR for both fuel experiments (see Figure $7 \mathrm{a}$ and $7 \mathrm{~b}$ ). As expected, somewhat higher fluxes occur in propane fuel experiments in the region below flame height, whereas very comparable heat fluxes were found above flame height region for both fuel experiments. One reason may be explained that propane fuel has higher radiative component of the heat release rate $\left(\chi_{\mathrm{rad}}=\dot{\mathrm{Q}}_{\mathrm{rad}}^{\prime \prime} / \dot{\mathrm{Q}}_{\mathrm{T}}^{\prime \prime}\right)$ and sooty yields $\left(\mathrm{y}_{\mathrm{s}}\right)$, which is the dominant heat transfer mechanism from flames to façade within the combustion region, compared with methane fuel [20]. . After the burning is completed, heat exposed to the façade is transferred only by convection.

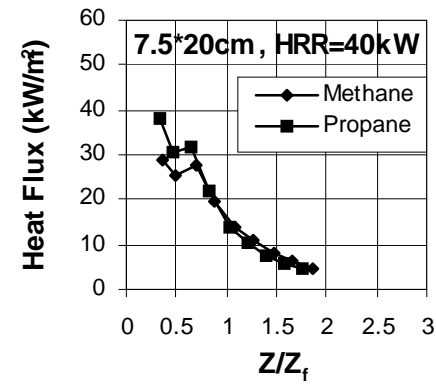

Fig. $7 \mathrm{a}$



Fig. $7 \mathrm{~b}$



Fig. 7c

Fig. 7a,7b,7c. Comparison of heat flux distribution along the centerline above the opening betweenmethane and propane fuel experiment for the case having one box enclosure geometry

\section{OFF-CENTER HEAT FLUX AND MAXIMUM FLAME WIDTH}

Correlations of the flame height and the centerline heat flux have been presented elsewhere $[16,17]$ where also the length scales $\ell_{1}$ and $\ell_{3}$ associated with this flow are defined as below.

$$
\begin{aligned}
& \ell_{1}=\left(\mathrm{AH}^{1 / 2}\right)^{2 / 5} \\
& \ell_{3}=\left(\mathrm{AH}^{4 / 3}\right)^{3 / 10}
\end{aligned}
$$

where

A and $\mathrm{H}$ are the area and height of the opening, respectively.

$\ell_{1}$ is the length scale related to the effective area of the outflow for under-ventilated fires $[16,17]$

$\ell_{3}$ is the length scale represented the length after which flames turn from horizontal to vertical due to buoyancy for under-ventilated fires $[16,17]$

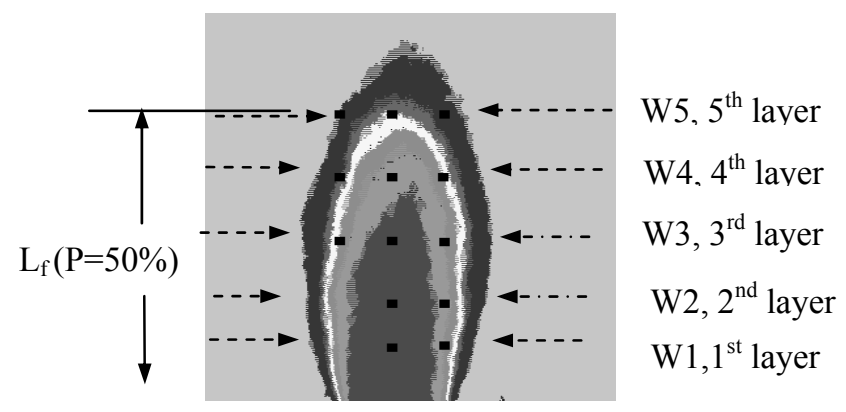

Fig. 8. Flame presence probability contour and flame width at the levels of heat flux gauge (2A, HRR: $60 \mathrm{~kW}$, Opening size : $0.1 \mathrm{~m}$ by $0.25 \mathrm{~m}$ ). 
The off-center heat flux distribution in the wall within the combustion region at different levels above the opening has been calculated by interpolation of an assumed parabolic profile using the three measurements at each height from the opening (see Fig. 2). Moreover, based on the same definition as for the mean flame height [2], the width of the combustion region has been determined at the location where the flame presence probability is equal to $50 \%$. For example, the profile obtained by the contour of the probability of the flame presence is illustrated in Fig. 8. Correlation of off-center heat fluxes and correlation of the flame width are discussed in the following section, respectively.

\section{Correlation of the Off-Center Heat Fluxes below the Flame Height}

Modeling of the heat fluxes by radiation is based on the following propositions

a) The radiant fraction from the flames on the façade which is generated by the heat released outside the enclosure is constant as the scale increases as it has been shown for buoyant turbulent flames ([22]) except for very large pool fires where the radiant fraction decreases owing to radiation blockage.

b) The flame height characterizes the distribution of the radiant output per unit height from which the heat fluxes to the surface emanate.

Based on these propositions, the heat fluxes at the centerline of the façade are well modelled essentially by the function below which also was shown $[16,17]$ to predict well the heat fluxes in the large scale facade experiments in [5]:

$\frac{\dot{\mathrm{q}}_{\text {Center }, \mathrm{Z}}^{\prime} \mathrm{Z}_{\mathrm{f}}}{\dot{\mathrm{Q}}_{\mathrm{ext}}}$ function of $\left(\frac{\mathrm{Z}}{\mathrm{Z}_{\mathrm{f}}}\right)$

Where $\dot{\mathrm{Q}}_{\mathrm{ext}}=\dot{\mathrm{Q}}_{\mathrm{th}}-1500 \mathrm{AH}^{1 / 2}$ is the heat released outside the enclosure for the present under-ventilated fires.

The following analysis is an extension of this modelling.

The lateral heat flux can be expressed by the following expression:

$\dot{\mathrm{q}}_{\mathrm{y}, \mathrm{Z}}^{\prime \prime}=\mathrm{fcn}\left(\dot{\mathrm{q}}_{\text {Center }, \mathrm{Z}}^{\prime \prime}, \mathrm{Z}_{\mathrm{f}}, \mathrm{y}, \ell_{1}, \ell_{3}\right)$

where

$\dot{\mathrm{q}}_{\mathrm{y}, \mathrm{Z}}^{\prime \prime}$ is the lateral heat flux at a distance $\mathrm{y}$ away from the certerline at the height $\mathrm{Z}$ above the opening

$\dot{\mathrm{q}}_{\mathrm{Center}, Z} \mathrm{Z}$ is the heat flux of the centreline at the distance $\mathrm{Z}$ above the opening

$\mathrm{Z}_{\mathrm{f}}$ is the mean flame height

$\mathrm{y}$ is the lateral distance away from the centreline of the opening

A dimensionless correlation function for the lateral heat fluxes is expressed as:

$\frac{\dot{\mathrm{q}}_{\mathrm{y}, \mathrm{Z}}^{\prime \prime}}{\dot{\mathrm{q}}_{\text {Center }, \mathrm{Z}}^{\prime}}=\operatorname{fcn}\left(\frac{\mathrm{y}}{\ell_{1}}, \frac{\mathrm{Z}_{\mathrm{f}}}{\ell_{1}}, \frac{\ell_{1}}{\ell_{3}}\right)$

Approximately, $\ell_{1} \approx \ell_{3}$, Eq. 7 can be rewritten as:

$\frac{\dot{\mathrm{q}}_{\mathrm{y}, \mathrm{Z}}^{\prime \prime}}{\dot{\mathrm{q}}_{\mathrm{Center}, \mathrm{Z}}^{\prime \prime}}=\mathrm{fcn}\left(\frac{\mathrm{y}}{\ell_{1}}, \frac{\mathrm{Z}_{\mathrm{f}}}{\ell_{1}}\right)$

Fig. 9 shows the plot of correlation of the off-center heat fluxes in the combustion region for three different experiments by using the following correlation equation 
$\frac{\dot{\mathrm{q}}_{\mathrm{y}, \mathrm{Z}}^{\prime \prime}}{\dot{\mathrm{q}}_{\text {Center }, \mathrm{Z}}^{\prime}}=\exp \left(-\left(\frac{\mathrm{y}}{\ell_{1}}\right)^{2}\right)$

It is observed that experimental data correlated well for the lateral heat flux within the combustion region using Eq. 9. This implies that the ratio $Z_{\mathrm{f}} / \ell_{1}$ in Eq. 8 does not significantly influence the lateral heat flux correlation.



Fig. 9. Correlation of the off-center heat fluxes in the combustion region. (Note: $1^{\text {st }}, 2^{\text {nd }}, 3^{\text {rd }}$ and $4^{\text {th }}$ are the first, the second, the third and the fourth layer of the steel plate gauge above the top of the opening (see Fig.8), respectively)

\section{Correlation of the Maximum Width of External Flames}

Based on the illustration shown in Fig. 8, the maximum flame width for experiments having different opening geometries and various gas supply rate were listed in Table 2. It is observed from Table 2 that the maximum width of the flame increases with flame height in the case of $\mathrm{W} / \mathrm{H} \leq 1$, while it keeps constant for $1<\mathrm{W} / \mathrm{H} \leq 2$. Two parameters will affect the maximum width of the flame. One is the flame height $\left(\mathrm{Z}_{\mathrm{f}}\right)$, the other is the aspect ratio of the opening $(\mathrm{W} / \mathrm{H})$. The latter parameter, $\mathrm{W} / \mathrm{H}$, can be more exactly expressed as the effective area of the outflow through an opening, which can be characterize by the length scale $\ell_{1}$. Therefore, the maximum width of the flame can be expressed as the following function

$\mathrm{W}_{\mathrm{f}, \max }=\mathrm{fcn}\left(\mathrm{Z}_{\mathrm{f}}, \ell_{1}\right)$

Based on Eq. 10, a dimensionless correlation equation for the maximum width of the flame is:

$\frac{\mathrm{W}_{\mathrm{f}, \max }}{\mathrm{Z}_{\mathrm{f}}}=\mathrm{fcn}\left(\frac{\ell_{1}}{\mathrm{Z}_{\mathrm{f}}}\right)$

Fig. 10 shows the plot of the correlation curve based on Eq. 11. It would appear that the correlation consists of two regions. One is nearly constant when $\ell_{1} / Z_{\mathrm{f}}$ is less than 0.16 and the other is then increase lineally with $\ell_{1} / Z_{\mathrm{f}}$. This correlation curve is valid in the case having an aspect ratio of the opening $(\mathrm{W} / \mathrm{H})$ between 0.375 and 2 .

Table 2. Maximum flame width for the experiments having different opening geometries and various gas supply rate

\begin{tabular}{|c|c|c|c|c|c|c|c|}
\hline $\begin{array}{l}\text { Opening } \\
\left(\mathrm{W}^{*} \mathrm{H}\right)\end{array}$ & $\dot{\mathrm{Q}}_{\mathrm{th}}$ & $\begin{array}{c}\mathrm{Z}_{\mathrm{f}} \\
(\mathrm{cm})\end{array}$ & $\mathrm{W}_{\mathrm{f}, \max }(\mathrm{cm})$ & $\begin{array}{c}\text { Opening } \\
\left(\mathrm{W}^{*} \mathrm{H}\right)\end{array}$ & $\dot{\mathrm{Q}}_{\mathrm{th}}$ & $\begin{array}{c}\mathrm{Z}_{\mathrm{f}} \\
(\mathrm{cm})\end{array}$ & $\mathrm{W}_{\mathrm{f}, \text { max }}(\mathrm{cm})$ \\
\hline \multirow{3}{*}{$\begin{array}{c}7.5 * 20 \\
\mathrm{~cm}\end{array}$} & $2 \mathrm{~A}, 40 \mathrm{~kW}$ & 79.9 & 21.3 & \multirow{2}{*}{$\begin{array}{c}20 * 20 \\
\mathrm{~cm}\end{array}$} & $2 \mathrm{~A}, 50 \mathrm{~kW}$ & 59.6 & 26.5 \\
\hline & $2 \mathrm{~A}, 50 \mathrm{~kW}$ & 92 & 23.3 & & $2 \mathrm{~A}, 60 \mathrm{~kW}$ & 68.8 & 28.8 \\
\hline & $2 \mathrm{~B}, 60 \mathrm{~kW}$ & 97.5 & 26 & \multirow{2}{*}{$20 * 13.3 \mathrm{~cm}$} & $1 \mathrm{~A}, 30 \mathrm{~kW}$ & 57.6 & 23.5 \\
\hline \multirow{3}{*}{$\begin{array}{c}10 * 25 \\
\mathrm{~cm}\end{array}$} & $2 \mathrm{~A}, 40 \mathrm{~kW}$ & 55.4 & 23.6 & & $1 \mathrm{~A}, 40 \mathrm{~kW}$ & 81.4 & 23.5 \\
\hline & $2 \mathrm{~A}, 50 \mathrm{~kW}$ & 70.5 & 25.5 & \multirow{2}{*}{$\begin{array}{c}20 * 10 \\
\mathrm{~cm}\end{array}$} & $1 \mathrm{~A}, 23.1 \mathrm{~kW}$ & 69.3 & 20 \\
\hline & $2 \mathrm{~A}, 60 \mathrm{~kW}$ & 81.6 & 26.8 & & $1 \mathrm{~A}, 30 \mathrm{~kW}$ & 80.4 & 20 \\
\hline
\end{tabular}






Fig. 10. The correlation of maximum width of the flame based on Eq. 11

\section{FLAME SHAPES ON EXTERNAL INERT FAÇADE}

Figures 11 and 12 show the correlation of flame height and pictures of the contour of the probability of the flame presence along the flame height correlation [16], respectively. In order to display the effect of opening geometry and HRR of the burner on the flame shape (height and width) on the façade, dimensionless contours of the probability of the flame presence having the same reference level (neutral plane corresponding to each experiment) shown in Fig. 12 were made of by the following procedures.

1. Scaling each flame presence probability contour in both lateral and vertical directions by its corresponding length scale $\ell_{1}$

2. Moving each picture up a distance of $0.6 \mathrm{H} / \ell_{1}$ ( $\mathrm{H}$ is the height of the opening which is corresponding to each experiment). The dot line below each picture represents the location of the neutral plane.

By inspecting the pictures shown in Fig. 12, it can be observed that the flame height $\left(Z_{\mathrm{f}}\right)$ increase relatively with the dimensionless heat release rate $\left(\dot{\mathrm{Q}}^{*} \ell_{1}\right)$ which is dominated by the chemical energy $\dot{\mathrm{Q}}_{\mathrm{ext}}$ generated by the combustion of the unburned gas ejected from the opening and the opening geometry. Thus, the physical meaning of correlation of flame height (Fig. 11) is able being explained by pictures shown in Fig. 12.

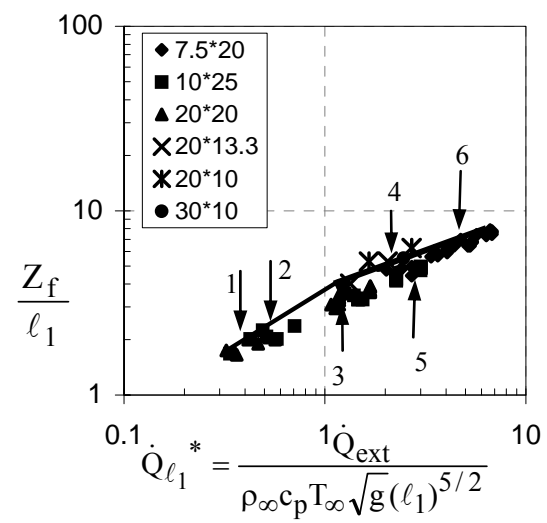

Fig. 11. Mean flame height correlation by using length scale $\ell_{1}$ presented in [16]. 



$1 \mathrm{~A}, 20 * 20,40 \mathrm{~kW}$
$1 \mathrm{~A}, 10 * 25,30 \mathrm{~kW}$
$2 \mathrm{~A}, \quad 20 * 20,50 \mathrm{~kW}$

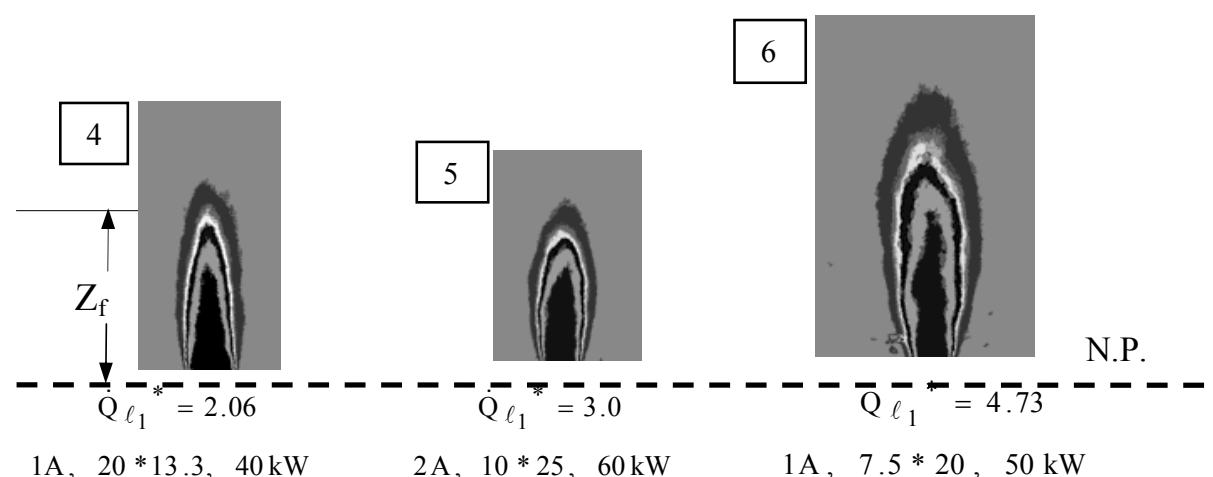

Fig.12. Flame Presence Probability Contour of CCD Images for the experiments shown in Fig.11 (N.P.: the location of the neutral plane where is $0.4 \mathrm{H}$ measured from the bottom of the opening)

\section{CONCLUSIONS:}

The major conclusions of this paper are:

1. A new steel plate probe (see Fig.3) $[16,17]$ calibrated and validated by comparing with Gardon gauge was employed to measure the heat fluxes in the façade.

2. The heat release rate inside the enclosure was verified to be $1500 \mathrm{AH}^{1 / 2}(\mathrm{~kW})$ for the under-ventilated fire experiments using propane and methane gas fuel (See Fig. 4)

3. A correlation for the lateral heat flux away from the centreline below the flame height was developed in Fig. 9. This equation in conjunction with the previous correlation on the centreline of the façade [17] can be used to predict the heat fluxes on the façade for any scale.

4. A correlation of the maximum flame width was proposed in Fig. 10 which is valid in the case having an aspect ratio of the opening (width to height) between 0.375 and 2 . Also, the flame shape on the façade for the cases having various opening geometry and HRR of the burner were displaced in Fig. 12.

\section{REFERENCES:}

[1] Hasemi, Y, "Experimental Wall Flame Heat Transfer Correlations For The Analysis of Upward Wall Flame Spread", Fire Science and Technology, Vol.4, Pt. 2, pp. 75-90, 1984

[2] Coutin, M., Most, J.M., Delichatsios, M.A. and Delichatsios, M.M., "Flame Heights in Wall Fires: Effects of Width, Confinement and Pyrolysis Length", Fire Safety Science, Proceedings of the 6th International Symposium, pp. 729-740, 2000

[3] Ahmad, T. and Faeth, G.M., "Turbulent Wall Fires", 17th Symposium (International) on Combustion", The Combustion Institute, pp. 1149-1160, 1979.

[4] Bohm, B. and Rasmussen, B.M., "The Development of a Small-scale Fire Compartment in Order to Determine Thermal Exposure Inside and Outside Buildings", Fire safety Journal, Vol. 12, pp. 103-108, 1987.doi:10.1016/0379-7112(87)90026-9

[5] Oleszkiewicz, I., "Heat Transfer from a Window Fire Plume to a Building Façade", HTD-Vol. 123, Collected papers in Heat Transfer, Book No. H00526, pp. 163-70, 1989. 
[6] Ohmiya, Y., Yusa, S., Suzuki, J.I., Koshikawa, K. and Delichatsios, M.A., “Aerothermodynamics of Fully Involved Enclosure Fires Having External Flames", 4th International Seminar, Fire and Explosion Hazards, pp.121-129, 2003.

[7] Quintiere, J.G. and Cleary, T.G., "Heat Flux from Flames to Vertical Surfaces", Fire Technology, Vol. 30, pp. 209-231, 1994.doi:10.1007/BF01040003

[8] Ahmad, T., "Investigation of the Combustion Region of Fire-Induced Plumes Along Upright Surface”, Ph.D. Thesis, The Pennsylvania State University, 1978.

[9] Ingason, H. and Ris J.D., "Flame Heat Transfer in Storage Geometries", Fire Safety Journal, Vol. 31, pp.39-60, 1998.doi:10.1016/S0379-7112(97)00062-3

[10] Dillon, S. E., "Analysis of the ISO 9705 Room/Corner Test : Simulations, Correlations and Heat Flux Measurements”, U.S. Department Commerce, NIST, NIST GCR 98-756, 1998.

[11] Delichatsios, M.A. and Liu, X., "Temperatures and Heat Fluxes in Corridors Owing to Room Fires", INTERFLAM 2001, pp. 1323-1330.

[12] Tofilo, P., Delichatsios, M.A., Silcock G.W.H. and Shields T.J., "Wall Heat Fluxes in Enclosure Fires", the 6th Asia-Oceania Symposium on Fire Science \& Technology, pp. 108-119, 2004.

[13] Huggett, C.,"Estimation of Rate of Heat Release by Means of Oxygen Consumption Measurements", Fire and Materials, Vol. 4, No. 2, pp. 61-65, 1980.doi:10.1002/fam.810040202

[14] Coutin, M., Most, J.M., Delichatsios, M.A. and Delichatsios, M.M., "Flame Heights in Wall Fires: Effects of Width, Confinement and Pyrolysis Length", Fire Safety Science, Proceedings of the 6th International Symposium, pp. 729-740, 2000.

[15] Audouin, L, Kolb, G., Torero, J. L. and Most, J. M, “Average Centerline Temperatures of Buoyant Pool Fire Obtained by Image Processing of Video Recordings”, Fire Safety Journal, Vol. 24, pp. 167-187, 1995.doi:10.1016/0379-7112(95)00021-K

[16] Lee, Yee-Ping, "Heat Fluxes and Flame Height in External Facades from Enclosure Fires", Ph.D. Thesis, the University of Ulster, 2006.

[17] Lee Yee-Ping, Delichatsios, M.A. and Silcock, G.W.H., "Heat Fluxes and Flame Heights in Facades from Fires in Enclosures of Varying Geometry", Proceedings of the Combustion Institute. 31(2), pp 2521-2528, 2007.doi:10.1016/j.proci.2006.08.033

[18] Klopovic, S. and Turan, O., "Flames Venting Externally During Full-Scale Flashover Fires: Two Sample Ventilation Cases", Fire Safety Journal, Vol. 31, pp. 117-142, 1998. doi:10.1016/S0379-7112(97)00065-9

[19] M.A. Delichatsios, J. De Ris and L. Orloff, "An Enhanced Flame Radiation Burner", Fire Safety Science, 24th Symposium on Combustion, The Combustion Institute, pp 1075-1082, 1992.

[20] SFPE Handbook of Fire Protection Engineering, 1995, pp. 3-78.

[21] Karlsson B. and Quintiere J. G., "Enclosure Fire Dynamics”, CRC Press LLC, 2000.

[22] Delichatsios, M.A., "Flame Heights in Turbulent Wall Fires with Significant Flame Radiation", Combustion Sci. and Technology, Vol. 39, pp. 195-214, 1984. doi:10.1080/00102208408923789 